\title{
Using Energy-Filtered TEM to Solve Practical Materials Problems with Inspirations from Gareth Thomas
}

Joshua D. Sugar ${ }^{1}$, Farid El Gabaly ${ }^{1}$, William Chueh $^{2}$, Kyle Fenton ${ }^{3}$, Paul G. Kotula ${ }^{3}$, Velimir

Radmilovic $^{6}$, Norman C. Bartelt ${ }^{1}$, Joseph T. McKeown ${ }^{4}$, Andreas M. Glaeser ${ }^{5}$, and Ron Gronsky ${ }^{5}$

${ }^{1}$ Sandia National Laboratories, Livermore, CA, USA

${ }^{2}$ Materials Science and Engineering, Stanford University, Stanford, CA, USA

${ }^{3}$ Sandia National Laboratories, Albuquerque, NM, USA

${ }^{4}$ Lawrence Livermore National Laboratory, Livermore, CA, USA

${ }^{5}$ Materials Science and Engineering, University of CA, Berkeley, CA, USA

${ }^{6}$ Nanotechnology and Functional Materials Center, University of Belgrade, Belgrade, Serbia

Gareth Thomas' legacy, scientific accomplishments, and inspirational reach extended beyond his own students to his students' students, as evidenced by the work discussed here. One topic researched by Gareth Thomas during his extensive career was the spinodal decomposition of Cu-Ni-Fe alloys [1-3]. Diffraction-contrast imaging was used to study the effects of composition and coarsening on the modulated structure that naturally develops in $\mathrm{Cu}-\mathrm{Ni}-\mathrm{Fe}$ alloys. An example from this work is shown in Figure 1 a). In subsequent work, graduate students under the direction of a former student of Thomas (R. Gronsky) studied the effects of volumetric encapsulation on the coarsening and compositional modulation of $\mathrm{Cu}-\mathrm{Ni}-\mathrm{Fe}$ alloys [4]. The utilization of a post-column energy filter to the TEM supplemented the original diffraction-based measurements performed by Thomas et al., enabling direct imaging of the compositional modulation, as shown in the corresponding zero-loss image in Figure 1 b) and overlaid elemental maps in Figure 1 c). In this way, it was possible to show that the decomposition reaction could be geometrically directed, as shown by the single domain of modulation in Figure 1 c). This work in the $\mathrm{Cu}-\mathrm{Ni}-\mathrm{Fe}$ system initiated the discovery of the importance of TEM to solving materials problems to the present authors, and the microscopy skills developed became essential to the follow-on work that the authors encountered.

One example of later work where energy-filtered TEM (EFTEM) was used to understand materials microstructure and properties is demonstrated in Figure 2 with battery electrode research. In this case, the analytical microscopy techniques developed for $\mathrm{Cu}-\mathrm{Ni}-\mathrm{Fe}$ alloys were further perfected to determine and map the valence of the $\mathrm{Fe}$ ion in $\mathrm{LiFePO}_{4}$ battery electrodes. This information was needed to determine that the charge/discharge reaction occurs particle-by-particle in $\mathrm{LiFePO}_{4}[5,6]$. Figure 2 is one example showing that the individual $\mathrm{LiFePO}_{4}$ particles in the electrode are either fully charged or fully discharged. It is rare to find a single particle with an interphase boundary. This suggests that nucleation is the limiting factor in controlling the charge/discharge rate in $\mathrm{LiFePO}_{4}$ cathodes. Without Gareth Thomas' influence on the direction of materials science and electron microscopy at the University of CA, Berkeley, and the original $\mathrm{Cu}-\mathrm{Ni}-\mathrm{Fe}$ work, the inspiration and capabilities needed to perform the battery electrode characterization shown here would not have existed.

References:

[1] R. Gronsky and G. Thomas, Acta Metallurgica 23 (1975), p. 1163-1171.

[2] R. J. Livak and G. Thomas, Acta Metallurgica 19 (1971), p. 497-505.

[3] R. J. Livak and G. Thomas, Acta Metallurgica 22 (1974), p. 589-599. 
[4] J. D. Sugar, et al., Acta Materialia 58 (2010), p. 5332-5341.

[5] J. D. Sugar, et al., Journal of Power Sources 246 (2014), p. 512-521.

[6] W. C. Chueh, et al., Nano Letters 13 (2013), p. 866-872.

[7] Sandia National Laboratories is a multi-program laboratory managed and operated by Sandia Corporation, a wholly owned subsidiary of Lockheed Martin Corporation, for the U.S. Department of Energy's National Nuclear Security Administration under contract DE-AC04-94AL85000.
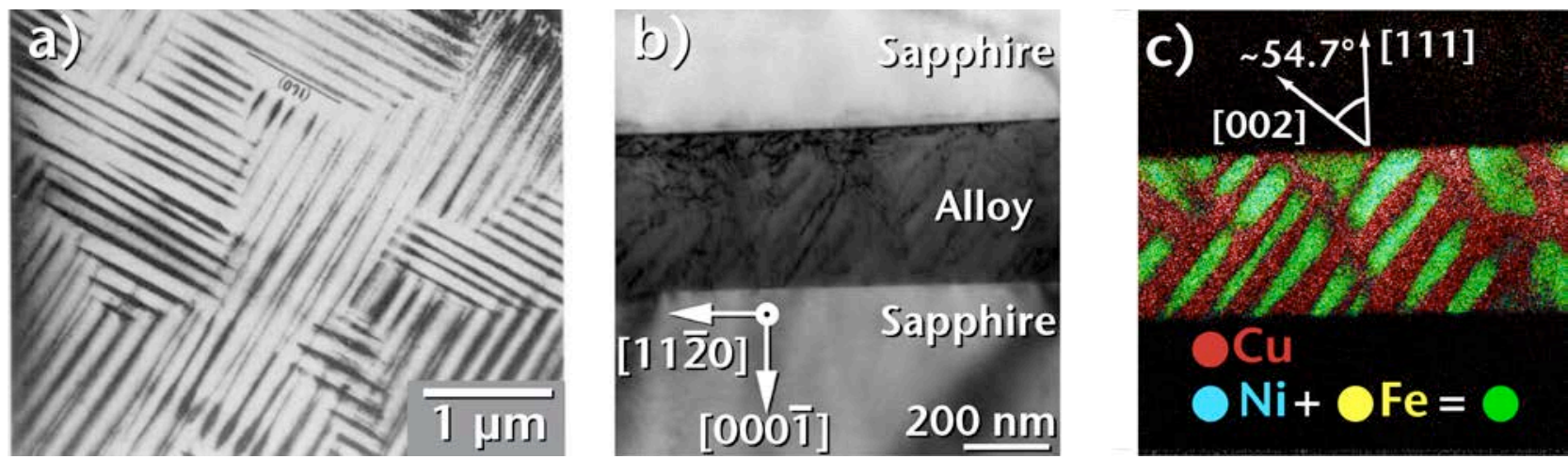

Figure 1. (a) Bright-field TEM image of $\mathrm{Cu}-\mathrm{Ni}-\mathrm{Fe}$ alloy aged $100 \mathrm{hr}$ at $800^{\circ} \mathrm{C}$, clearly showing the modulated compositional structure (from [3]). In (b), a zero-loss image of the $\mathrm{Cu}-\mathrm{Ni}-\mathrm{Fe}$ alloy encapsulated in sapphire and annealed for $188 \mathrm{hr}$ at $700^{\circ} \mathrm{C}$ is shown. The corresponding compositional modulation is shown in the overlaid energy-filtered maps shown in (c).

a)

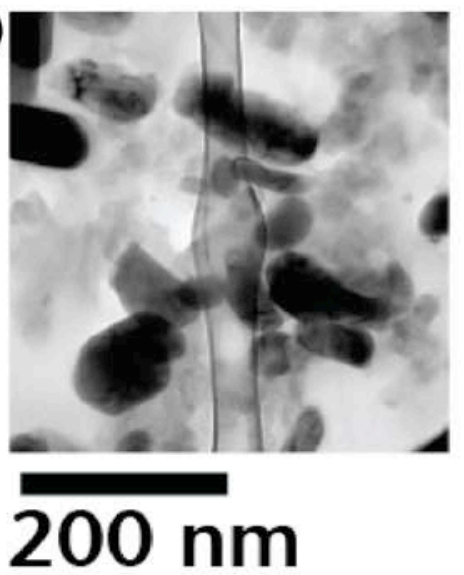

b)

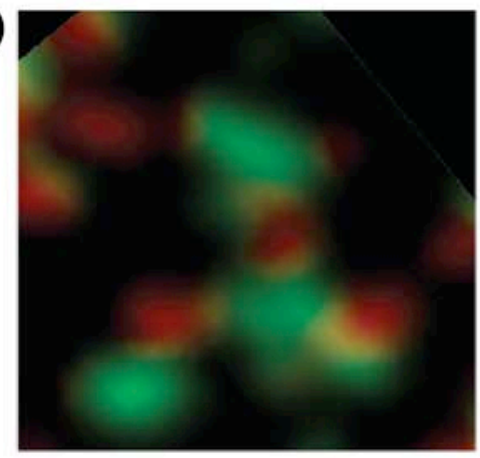

$\mathrm{Fe}^{2+}\left(\mathrm{LiFePO}_{4}\right)$ c)



$\mathrm{Fe}^{3+}\left(\mathrm{FePO}_{4}\right)$

Figure 2. (a) Bright-field TEM image of particles in a partially charged $\mathrm{LiFePO}_{4}$ battery electrode. The Fe valance is mapped using scanning transmission x-ray microscopy (STXM) in (b) and energy-filtered TEM (EFTEM) in (c). Both techniques are in good agreement. 